\title{
Implementation of talis and dc house system for rural areas in indonesia
}

\author{
Dwi Riana Aryani ${ }^{1}$, Faiz Hunsnayain ${ }^{1}$, Andres Pramana Edward ${ }^{1}$, Hwachang Song ${ }^{2}$, \\ Yoyok Dwi Setyo Pambudi ${ }^{1}$, Anne Zulfia, ${ }^{3,4}$, and Chairul Hudaya ${ }^{1,4^{*}}$ \\ ${ }^{1}$ Dept. of Electrical Engineering, Universitas Indonesia, Depok, Jawa Barat, 16424, Indonesia \\ ${ }^{2}$ Dept. of Electrical and Information Engineering, Seoul National University of Science and \\ Technology, 232 Gongneung-ro, Nowon-gu, Seoul, 01811, Republic of Korea \\ ${ }^{3}$ Dept. of Metallurgy and Materials Engineering, Universitas Indonesia, Depok, Jawa Barat, 16424, \\ Indonesia \\ ${ }^{4}$ Energy System Engineering, Faculty of Engineering, Universitas Indonesia, Depok, Jawa Barat, \\ 16424, Indonesia
}

\begin{abstract}
In 2017, the aggregate electrification ratio in Indonesia has been achieving $92.8 \%$. However, some rural areas such as in Maluku and Papua Islands still have low electrification ratio $(\sim 70 \%)$. One of the main problems in supplying electricity to rural areas in Indonesia is the geographical concern which consisted of islands leading to the difficulty of electricity grid development. In some areas, diesel power plant has been being built to supply the electricity. However, it causes another problem to transport the primary energy source to the targeted area which would increase the cost of electricity supply. Besides, it also needs investment cost to build transmission and distribution systems, as well as the maintenance expenses. To resolve this issue, a new scheme of batterybased Tabung Listrik or TaLis (DC-based power bank) and DC house system is proposed to be the solution to provide electricity to rural areas. The potential of local renewable energy sources such as biomass, hydro, wind, and solar could be utilized to be charging sources of batteries (TaLis). This study presents the TaLis prototype, DC house installation, supply chain process and charging scheme of TaLis, and cost comparison between the proposed system with other existing power systems such as communal PV farm and diesel power plant. We found that TaLis and DC house system provided the least cost of electricity production compared to other power systems, i.e. $\$ 0.88 / \mathrm{kWh}$ for TaLis and DC house system, $\$ 1.65 / \mathrm{kWh}$ for diesel power plant, and $\$ 1.47 / \mathrm{kWh}$ for communal PV farm. Implementation of this approach is expected to improve the welfare and quality of life of rural communities immediately.
\end{abstract}

\section{Introduction}

Conventional electric grids generate electricity using generators in alternating current (AC) form. In order to deliver electricity from power plants to consumers, transmission and

* Corresponding author: c.hudaya@eng.ui.ac.id 
distribution systems are needed at various voltage levels. In AC systems, it is easy to transform the voltage level with transformers [1]. However, this system has disadvantages as well, such as the existence of reactive power and skin effect which leads to power losses in transmitting and distributing electric power. Meanwhile, in direct current (DC) system there are no such issues so the efficiency of power transmission and distribution from power plants to consumers is higher compared to the AC system [2]. Besides, the improvement of renewable energy sources (RES) and DC loads makes DC power systems more feasible to be implemented in the future [3].

A concept of DC microgrid has been established as the evolvement of the renewable energy sources, DC loads, and energy storage systems. In [4], the scheme of power sharing and management for utility connected DC microgrid has been studied. While for isolated DC microgrid, a power control algorithm has been developed in order to attain effective energy management [5]. Another intelligent power control of DC microgrid based on fuzzy algorithm has been proposed as well [6]. For rural electrification, an efficient distribution architecture of solar PV based low-power low-voltage DC microgrid could be achieved with regards to the arrangements of houses [7]. In this study, another scheme to electrify rural areas without constructing transmission or distribution networks or microgrids is proposed, while the renewable energy sources, battery energy storage systems, and DC loads are implemented.

\section{The proposed system of TaLis and DC house}

This study proposes a simple scheme to deliver power in rural areas, from charging stations to consumers. The centralized charging stations might be supplied from any type of power plants, including conventional power plants and renewable energy sources. Here, we select solar power plant as the power source, in which the potential of solar energy in Indonesia reaches $4.8 \mathrm{kWh} / \mathrm{m} 2 /$ day or equivalent to $112,000 \mathrm{GWp}$ [8].

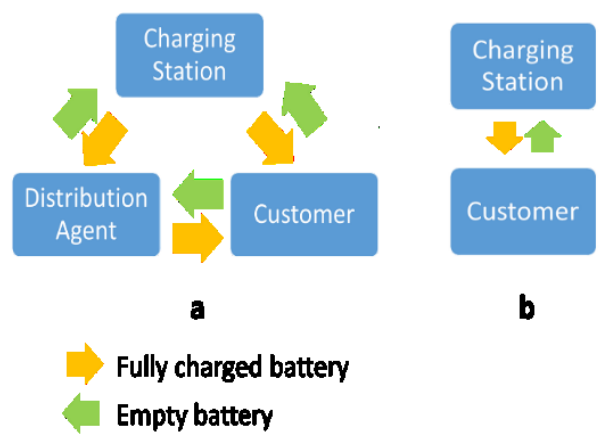

Fig. 1. Flow diagram of TaLis distribution and exchange scheme (a) with a distribution agent, and (b) without distribution agent

All loads are in DC form and this platform is known as DC house systems or DC low voltage house [9]. A new scheme introduced here is the battery bank known as TaLis which is distributed to all households as the power supply. This concept adopts the distribution of gas cylinder as well as mineral water in Indonesia, where the empty gas cylinders or mineral waters are returned to the distribution agents or supplier to be exchanged with the fully charged one. In the same manner, the "empty" TaLis can be exchanged with the fully charged one in the charging station or distribution agent. Distribution agents are then needed if the targeted location is considered too far from the charging station, more than 1 
$\mathrm{km}$. Within this scheme, transmission or distribution networks will not be needed, which significantly reduce the investment cost.

\subsection{DC house system}

In this system, the houses are proposed to utilize DC loads and DC electrical installation. DC house system here is popularized by Dr. Taufik, a Professor of California Polytechnic State University. This system is proposed for rural electrification which is expected to gradually educate people in rural areas about the benefits of electricity [10]. It has been tested as in [11] that $48 \mathrm{~V}$ is the most efficient system voltage when the percent loading was varied. For electric equipment or home appliances with different voltage level, it would require a DC/DC converter. Table 1 shows the assumption of daily consumption for each household in rural areas.

Table 1. Assumption of average daily energy consumption for a single household

\begin{tabular}{|c|l|c|c|c|c|}
\hline No & \multicolumn{1}{|c|}{ Electric Equipment } & Unit & $\begin{array}{c}\text { Power } \\
\text { (Watt) }\end{array}$ & $\begin{array}{c}\text { Usage } \\
\text { (Hour) }\end{array}$ & $\begin{array}{c}\text { Energy } \\
\text { (Wh) }\end{array}$ \\
\hline 1 & LED lights & 4 & 7 & 5 & 140 \\
\hline 2 & Television & 1 & 50 & 4 & 200 \\
\hline 3 & Fan & 1 & 30 & 3 & 90 \\
\hline 4 & Others (Hand phone charger, Radio) & 1 & 40 & 3 & 120 \\
\hline \multicolumn{4}{|c|}{ Total daily energy consumption } \\
\hline
\end{tabular}

\subsection{TaLis/ battery bank}

Figure 2 shows the concept of TaLis main components which consists of 18650 typed lithium-ion batteries arranged in series and parallel, battery management system (BMS), and covered by battery pack from steel plate. In general, a 18650 lithium-ion cell has the capacity around $2.2-3$ Ah with nominal voltage $3.7 \mathrm{~V}$. There is 13 battery in series and 4 sets of those batteries are connected in parallel. Thus, there are 52 battery cells in total for one battery bank.

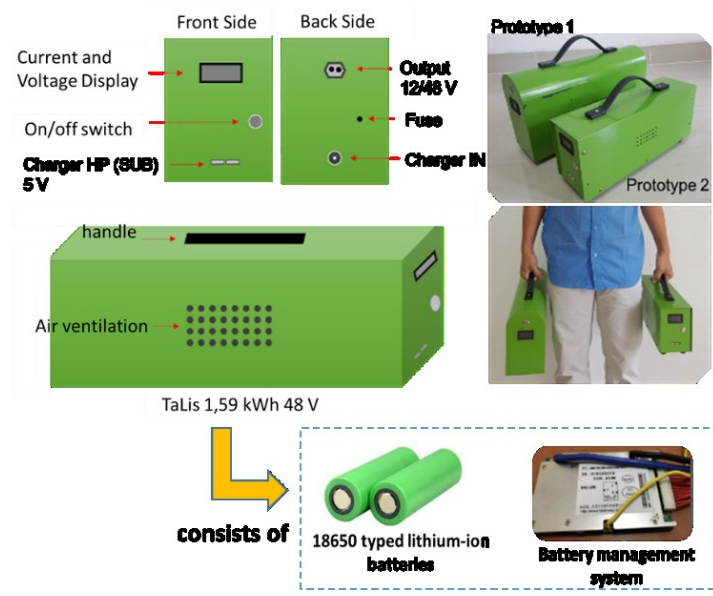

Fig. 2. TaLis main components consist of 18650 typed lithium-ion batteries arranged in series and parallel, battery management system (BMS), and covered by battery pack from steel plate.

By using that configuration, each battery bank is able to store $0.58 \mathrm{kWh}$ energy with voltage $48.1 \mathrm{~V}$. The battery bank is connected by nickel plate in its positive and negative 
polarities using spot welding systems. It is equipped by BMS as well for protecting and monitoring the battery states.

If the daily energy consumption of the households follows the assumption in Table 1, with the designed battery capacity as in $2.2(0.58 \mathrm{kWh} /$ battery bank $)$, it is estimated that the battery needs to be charged every day. Later for the implementation, the TaLis capacity could be increased up to $1.59 \mathrm{kWh}$ to reduce the charging cycle numbers and prolong the battery lifetime.

\subsection{Charging stations}

There are several options of power sources for charging stations, such as fossil fuel power stations, nearby power utility grid, and renewable energy sources. In this study, the solar power plant is selected as the power source as it has a large potential in Indonesia. The solar irradiance and the temperature of the target location are also considered enough to generate the electricity by photovoltaic (PV) panels. Besides, it provides the most efficient cost of electricity compared to others.

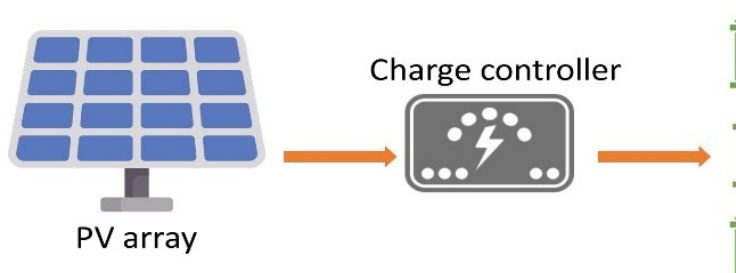

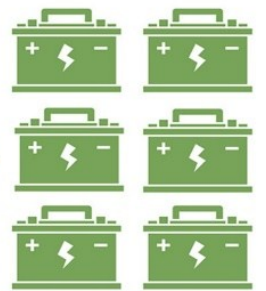

TaLis

Fig. 3. Power flow during the charging mode of TaLis

Figure 3 shows the load flow from PV array towards TaLis during the charging mode of TaLis. In the charging station, TaLis' are considered as the loads. A solar charge controller is needed to control power flowing from PV to TaLis. Capacity of the power plant depends on the numbers of TaLis distributed in the target location, where numbers of TaLis is depended on the total households in that area. For example, there are 120 houses in one area, meaning 120 packs of TaLis are provided. The total daily energy needed to charge TaLis or $E_{c h}$ in that area is:

$$
E_{c h}=n \times C_{\text {TaLis }}
$$

where $n$ is numbers of the distributed TaLis in that area and $C_{T a L i s}$ is TaLis capacity.

Using configuration in Fig. 4, there might be some losses resulting in the efficiency of cables and charge controller is less than $100 \%$. In this study, the system efficiency $(\eta)$ is assumed $85 \%$. Thus the energy flow from $\mathrm{PV}\left(E_{p v}\right)$ is:

$$
E_{p v}=E_{c h} / \eta
$$

The solar power plant capacity $\left(P_{p v}\right)$ with $h$ hours charging duration for a set of battery packs is

$$
P_{p v}=E_{p v} / h
$$


This capacity can be reduced if there is less amount of TaLis to be charged at one charging cycle. It means that the capacity of the solar power plant could be reduced into three fourth or even half of the total amount calculated above.

Using calculations in (1) - (3), it is found that for a region with 120 households and TaLis capacity $1.59 \mathrm{kWh}$, the total energy demand $E_{c h}$ is $190.8 \mathrm{kWh}$, while $E_{p v}$ with $\eta=$ 0.85 is $224.47 \mathrm{kWh}$. The required $P_{p v}$ for 4 hours charging duration is approximately 60 $\mathrm{kW}$.

\section{Cost comparison between the proposed system with existing power systems}

In this section, the cost of electricity using the proposed scheme of combined TaLis and DC House are compared with other existing power systems in some rural areas such as diesel power plant and communal solar power plant. This calculation is assumed for 20 years operation and the targeted area has 120 houses.

\subsection{Charging stations}

In this scheme, the cost of electricity is determined based on the cost of investment, construction, and operational and maintenance. Investment cost refers to some components required for charging station such as PVs, charge controllers, and TaLis chargers, as well as TaLis units. Some components need to be renewed at some particular times, such as TaLis' are replaced in every 7 years and chargers in every 10 years. The total investment cost for the combined TaLis and DC house in 20 years is $\$ 162,278$.

Construction for buildings in the charging station is renovated in 10 years, with renovation expense takes $50 \%$ of the beginning construction cost. The total construction cost for this system is $\$ 18,371$. Meanwhile, operational and maintenance cost is counted annually for 20 years, with a total $\$ 159,692$.

\subsection{Cost analysis for diesel power plant}

In case the power system in rural areas generates electricity using diesel power plants, the distribution lines, and towers or poles would be required. It means that the investment cost is used for the diesel generator set and distribution system components. Total investment cost is $\$ 25,017$. Construction cost is needed for the power plant which is only $38 \%$ of the proposed system construction cost, around $\$ 7,505$.

Operational and maintenance cost is higher than the proposed system, around $\$ 408,103$. This is due to the distribution system components, which leads to requiring more human resources. Besides, there is an additional cost for fuels of diesel machines which is usually more expensive than the normal cost due to the transportation fee to the rural areas, with a total $\$ 198,729$ for 20 years.

\subsection{Cost analysis for communal solar power plant}

In this system, the power source is the same as the proposed scheme, using PV panels with higher capacity even could reach ten times. This scheme also requires a distribution system, so the cost of operation and maintenance is higher than the proposed system, around $\$ 266,154$. The cost of investment is used for PV panels, batteries, charge controllers, inverters, and distribution system components, around $\$ 300,190$. Some equipment needs to 
be renewed as in the proposed system. The construction cost for this system is the highest among all since it requires large plant, around $\$ 43,798$.

After calculating all elements mentioned above, it is obtained that the cost of electricity for systems in $3.1,3.2$, and 3.3 are $\$ 0.88 / \mathrm{kWh}, \$ 1.65 / \mathrm{kWh}$, and $\$ 1.47 / \mathrm{kWh}$ respectively. Thus, the cost of electricity for the proposed system using the combined TaLis and DC House system is the most economical solution compared to others. Another way to attain optimum cost of electricity in the isolated area is by utilizing the hybrid system as presented in [12], especially as it was proposed for Papua Province.

\section{TaLis and DC house implementation}

TaLis and DC house system has been being implemented in a school in Depok since November 2017. Three units of TaLis with the total capacity around $1.9 \mathrm{kWh}$ and $3 \mathrm{kWp}$ rooftop solar panel are used to supply some DC loads (LED lamps) in a class as shown in Figure 4.

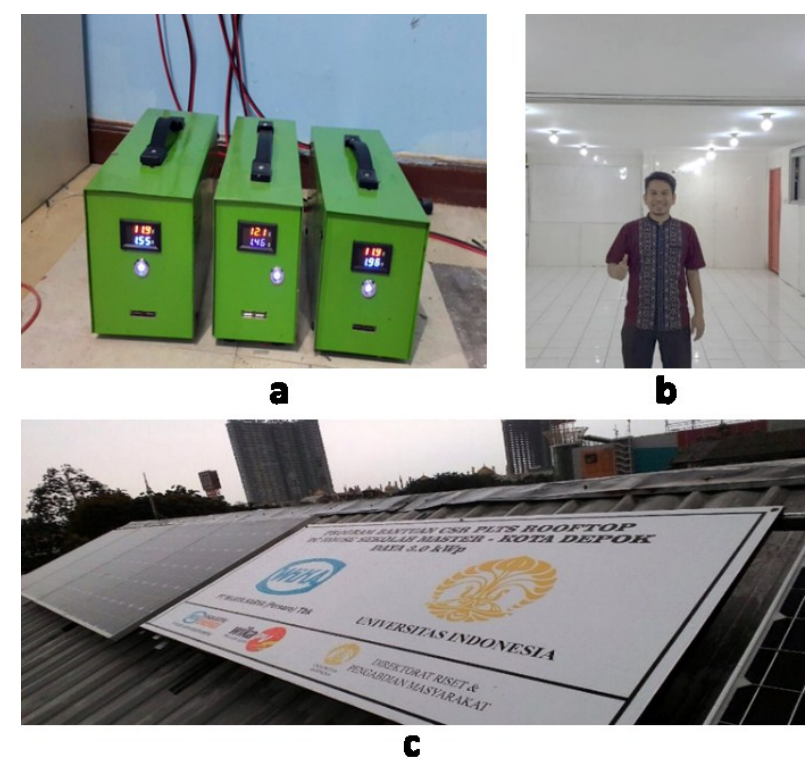

Fig. 4. Implementation of TaLis and DC House in a school; (a) three packs of TaLis as power supply, (b) DC lights supplied by TaLis in a classroom, and(c) rooftop solar panels as another power supply.

\section{Conclusion}

In this study, we proposed an approach to provide a reliable and economical solution to electrify rural areas in archipelago countries like Indonesia. TaLis and DC house system has a simple scheme to generate and deliver electricity from the power source to the consumer without requiring construction for transmission or distribution grid. The development of renewable energy sources and DC system including energy storages and DC loads also leads this system to be feasibly implemented. Compared to diesel power plant and communal solar power plant with the distribution network, the electricity production cost for TaLis and DC house system is cheaper. Moreover, the DC system is much more efficient and safer than the common AC system. 


\section{Acknowledgment}

This article's publication is supported by USAID through Sustainable Higher Education Research Alliances (SHERA) Project for Universitas Indonesia's SMART CITY Center for Collaborative Research (No. 0144/UN2.R3.SC/HKP.05.01/2018)

\section{References}

1. M. Larruskain, I. Zamora, A. J. Mazon, O. Abarrategui, J. Monasterio, "Transmission and Distribution Networks: AC versus DC" (2018)

2. A. Sannino, G. Postiglione, M. H. J. Bollen, "Feasibility of a DC Network for Commercial Facilities", IEEE Trans. Ind. Appl. 39, 1499-1507 (2003)

3. S. Backhaus, G. W. Swift, S. Chatzivasileiadis, W. Tschudi, S. Glover, M. Starke, J. Wang, M. Yue, D. Hammerstrom, "DC Microgrids Scoping Study-Estimate of Technical and Economic Benefits",LA-UR-15-22097 (March 2015)

4. A. J. Datta, A. Ghosh, S. Rajakaruna, "Power Sharing and Management in a Utility Connected DC Microgrid", Australasian Universities Power Engineering Conference (Melbourne, Australia, 2017)

5. P. Sanjeev, N. P. Padhy, P. Agarwal, "Effective Control and Energy Management of Isolated DC Microgrid”, IEEE Power \& Energy Society General Meeting (Chicago, IL, 2017)

6. A. Hajizadeh, M. Soltani, L. E. Norum, "Intelligent Power Control of DC Microgrid", IEEE 17th International Conference on Ubiquitous Wireless Broadband (Salamanca, 2017)

7. M. Hamza, M. Shehroz, S. Fazal, M. Nasir, H. A. Khan, "Design and Analysis of Solar PV Based Low-Power Low-Voltage DC Microgrid Architectures for Rural Electrification", IEEE Power \& Energy Society General Meeting (Chicago, IL, 2017)

8. Secretariat General of National Energy Council, Indonesia Energy Outlook 2016 (Jakarta, 2016)

9. M. Friedeman, A. Timmeren, E. Boelman, J. Schoonman, "Concept for a DC- Low Voltage House”, Smart \&amp; Sustainable Built Environments 8, 85-94 (Jan 2008)

10. Taufik, R. Muchtar, M. Taufik, "Performance Analysis of Multiple Input Boost Converter with Inherent OR Diode Configuration", International Seminar on Intelligent Technology and Its Applications 175-180 (2017)

11. J. E. Chaidez, "DC House Modelling and System Design", Senior Project of Electrical Engineering Department California Polytechnic State University (June 2011)

12. F. Ardin, A. Rahardjo and C. Hudaya, "Electricity Price and Subsidy Scenario for Hybrid Power Generations on off-Grid System", International Conference on Control, Electronics, Renewable Energy and Communications 132-138 (Yogyakarta, 2017) 